\title{
Analisis Penerapan Cost Containment pada Kasus Sectio Caesarea dengan Jaminan BPJS di RS Pemerintah XY di Kota Bogor Tahun 2016
}

\author{
Analysis of Cost Containment Implementation in Sectio Caesarea covered by BPJS in XY Public \\ Hospital, Bogor, 2016
}

\author{
Nazirah Istianisa ${ }^{1}$ Puput Oktamianti \\ Korespondensi: Nazirah Istianisa \\ e-mail: n.istianisa@gmail.com
}

${ }_{1}^{1}$ Program Studi Kajian Administrasi Rumah Sakit, Fakultas Kesehatan Masyarakat Universitas Indonesia

${ }^{2}$ Departemen Administrasi Kebijakan Kesehatan Universitas Indonesia

\begin{abstract}
Abstrak
Sistem pembayaran prospektif dengan paket tarif INA-CBG's untuk kasus dengan jaminan BPJS menuntut rumah sakit agar dapat melakukan kendali biaya. Penelitian ini bertujuan untuk menilai upaya Cost Containment RS XY melalui penerapan Clinical Pathway, formularium, dan struktur insentif. Studi dilakukan pada kasus Sectio Caesarea periode Januari-Maret 2016 secara kuantitatif dengan membandingkan selisih klaim BPJS dan tagihan RS serta menilai penerapan Clinical Pathway dan secara kualitatif dengan wawancara mendalam. Total Selisih yang didapat sebesar Rp.1.014.125.684,00 dengan rata-rata selisih sebesar Rp.4.899.157,89 per kasus. Didapatkan 84\% kasus memiliki length of stay sesuai Clinical Pathway (CP). Dari kasus tersebut, 96\% visitasi dokter sesuai, 21\% penggunaan obat dan BHP sesuaidengan, 48\% pemeriksaan laboratorium sesuai dengan yang ditentukan dalam CP. Formularium yang digunakan sesuai dengan formularium nasional. RS XY belum memiliki sistem evaluasi untuk menilai penerapan clinical pathway dan penggunaan obat. Struktur insentif yang digunakan adalah sistem fee-for-service pada staf medik yang tidak sesuai dengan metode pembayaran jasa medis yang prospektif. Kata kunci: Costcontainment; kendali biaya; pembayaran prospektif; tarif INA-CBG's
\end{abstract}

\begin{abstract}
Prospective payment system with INA-CBG's fare for cases using BPJS Insurance demands hospital to control their cost. This study aims to see the cost containment in XY Hospital through the implementation of clinical pathway, drug formulary, and incentive structure. The study looked into Sectio Caesarea cases from January to March 2016, using quantitative method, comparing BPJS claim with hospital billing and assesst the implementation of clinical pathwayusing qualitative method through in depth interview. Result shows there is deficit amount of Rp.1.014.125.684,00 and the average of deficit per case is Rp.4.899.157,89. Eighty four percent of cases have length of stay in accordance with clinical pathway. From those cases, $96 \%$ has concordant doctors visit, 21\% has concordant drug usage, and $48 \%$ has concordant laboratory diagnostic test. The hospital formulary uses the national formulary. It is found that XY Hospital does not have an evaluation system for clinical pathway implementation and drug usage. The incentive structure that is used is fee-for-service system which is not suitable for prospective payment method.

Keywords: Cost containment; cost control; prospective payment; INA-CBG's tariff
\end{abstract}

\section{Pendahuluan}

Amanah UU No. 40 tahun 2004 tentang Sistem Jaminan Sosial Nasional (UU SJSN), Indonesia menerapkan Jaminan Kesehatan Nasional (JKN) yang diselenggarakan oleh Badan Penyelenggaraan Jaminan Sosial (BPJS) Kesehatan dan diatur oleh UU No. 24 tahun 2011. BPJS Kesehatan membayar Fasilitas Kesehatan Tingkat Pertama (FKTP) dengan metode kapitasi. Pembayaran di Fasilitas Kesehatan Tingkat Lanjutan (FKTL) menggunakan Indonesia CaseBased Groups (INA-CBG's) sesuai dengan Peraturan Presiden No. 12 tahun 2013 tentang Jaminan Kesehatan sebagaimana telah diubah dengan Peraturan Presiden No. 111 tahun 2013 (Putri, 2014).

Pembayaran dengan INA-CBG's adalah metode pembayaran prospektif yang besaran tarifnya sudah diketahui sebelum pelayanan kesehatan diber- ikan. Sistem pembiayaan prospektif diharapkan dapat mengendalikan biaya kesehatan, mendorong pelayanan kesehatan tetap bermutu sesuai standar, membatasi pelayanan kesehatan yang tidak diperlukan, mempermudah administrasi klaim, dan mendorong provider untuk melakukan cost containment (Permenkes No 27 Tahun 2014).

Dalam menghadapi kompetisi pelayanan kesehatan, rumah sakit mungkin menggunakan satu dari strategi berikut (1) meningkatkan kualitas produk dan meningkatkan harga; (2) membuat produk dengan kualitas lebih rendah dengan harga lebih murah dan (3) meningkatkan kualitas dan di saat bersamaan menurunkan harga. Dalam ketiga strategi tersebut costcontainment memegang peranan penting sesuai dengan konsep "peningkatan kualitas yang efisien” (efficient quality improvement). Efisiensi 
merujuk pada proses minimisasi waste, error, dan redundancy (Pena \& Ndiaye, 2003). Cost containment adalah praktek meminimisasi sampai batas yang dimungkinkan, peningkatan berkala biaya variable dan total fixed cost per unit (Kinney \& Raiborn 2011).

Cost containment terbukti dapat mengeliminasi risiko kemungkinan menurunnya kualitas pelayanan jika pelayanan terlalu disederhanakan. RAND Health Insurance Experiment melakukan penelitian random terhadap keluarga dengan berbagai insuranceplan. Salah satu yang ditemukan adalah bahwa keluarga dengan insurance, paling kecil mengeluarkan biaya hampir 30\% dan lebih sedikit dalam pengeluaran biaya kesehatan dibandingkan dengan keluarga tanpa memiliki asuransi (Newhouse dalam Garber, 2007).

Menurut Dever dalam Pena \& Ndiaye (2003) komitmen pada peningkatakan mutu dapat menurunkan pengeluaran organisasi. Sekitar 20$30 \%$ dari pengeluaran organisasi disebabkan oleh redundancy dari upaya, error, pengerjaan ulang, masalah berulang, SDM tidak terlatih dan sistem yang kurang baik. Dalam upaya menekan health expenditure, beberapa negara menggunakan kriteria yang jelas dapat memicu cost-containment. Policy maker membuat beragam instrumen cost-containment (Carrin \& Hanvoravongchai 2002). Hal pertama yaitu membuat upaya yang berdampak langsung pada supply pelayanan kesehatan. Kedua, adalah upaya pengendalian pada sisi demand pelayanan kesehatan yang mempengaruhi perilaku pasien, baik melalui insentif non-moneter seperti promosi kesehatan dan informasi obat maupun insentif moneter seperti user fees.

Beberapa upaya penerapan cost containment untuk kendali mutu dan kendali biaya telah dilakukan RS XY seperti standardisasi obat, penerapan clinical pathway (CP), dan perhitungan biaya satuan dengan metode activity based costing. Secara umum RS XY mampu menekan biaya menjadi lebih kecil dari klaim INACBG's, namun biaya pelayanan kesehatan pada kasus tertentu lebih besar daripada klaim INA-CBG's seperti pada pelayanan tindakan Sectio Ceasarea (SC). Oleh karena itu, penelitian ini dilakukan dan bertujuan untuk menilai upaya costcontainment pada kasus Sectio Caesarea di RS XY melalui penerapan Clinical Pathway, formularium, dan struktur insentif.

\section{Metodologi Penelitian}

Penelitian ini menggunakan pendekatan kualitatif yang dilakukan di RS XY pada periode Mei 2016Juni 2016. Metode pengambilan data menggunakan data primer dan data sekunder. Pengambilan data sekunder dilakukan dengan telaah dokumen untuk memperoleh informasi mengenai penerapan cost containment khususnya untuk pelayanan pasien BPJS dengan prosedur SC. Telaah dokumen pada biaya RS dan klaim INA-CBG's RS dilakukan untuk melihat selisih tagihan Rumah Sakit kasus SC selama Januari-Maret 2015. Kemudian dilakukan telaah dokumen CP SC, bukti transaksi pasien dan data elektronik dari Sistem Informasi Rumah Sakit (SIRS) dan aplikasi INA-CBG's rumah sakit untuk mengetahui kesesuaian penerapan.

Pengambilan data primer dilakukan dengan wawancara mendalam. Informan diwawancarai untuk menelaah lebih lanjut mengenai penerapan cost containment, pengendalian obat dan Bahan Habis Pakai (BHP), pengendalian pemeriksaan penunjang, penerapan $\mathrm{CP}$, dan sistem insentif yang diterapkan di RS XY. Informan yang terdiri dari Wakil Direktur Pelayanan Medik, Wakil Direktur Umum dan Keuangan, Kepala Bagian Keuangan, Kepala Tim Pengendali JKN, SMF Obgyn, Kepala Instalasi Farmasi, Kepala Instalasi Laboratorium, Kepala Ruang Bersalin, Kepala Ruang Farmasi, dan Staf Instalasi Laboratorium.

Data perbandingan besaran klaim INA-CBG's dengan biaya rumah sakit, disajikan dalam bentuk tabel untuk menunjukkan selisih yang didapat. Dokumen CP SC selama periode Januari-Maret 2016 data menunjukkan bahwa ada 207 kasus yang termasuk ke dalam kelompok kode INA-CBG's O-6-10 yaitu prosedur operasi pembedahan Caesar dengan 170 kasus tingkat keparahan ringan dan 37 kasus tingkat keparahan sedang. Data dilihat dan dinilai kesesuaiannya setelah itu ditentukan kesesuaian length of stay (LOS) pasien. Dari kasus yang lama LOS sesuai dengan CP, ditelaah lagi kesesuaian visitasi dokter, penggunaan obat, dan pemeriksaan laboratorium. Data disajikan dalam tabel dan diagram untuk menunjukkan proporsi. Informasi kendali biaya SC di RS XY yang mencakup formularium, CP, dan sistem insentif dari hasil wawancara mendalam dikumpulkan dalam bentuk transkrip dan dipindahkan ke dalam matriks wawancara mendalam berdasarkan variabel penelitian kualitatif.

\section{Hasil Penelitian}

Kasus SC tanpa penyulit dengan jaminan BPJS Kesehatan sepanjang periode Januari-Maret 2016 didata, kemudian dijumlahkan besaran klaim yang didapatkan dengan menggunakan tarif INA-CBG's dan dibandingkan dengan biaya yang dikeluarkan pada kasus tersebut. Selanjutnya komponen biaya dihitung untuk mengetahui komponen pembentuk bi- 
aya terbesar. CP tindakan SC yang berlaku di RS XY juga dievaluasi penerapannya dari segi lama rawat, visitasi dokter, penggunaan obat dan BHP, serta pemeriksaan laboratorium.

Terdapat beberapa keterbatasan dalam pelaksanaan penelitian anatara lain Rumah Sakit belum mempunyai sistem informasi yang memungkinkan peneliti untuk menghitung biaya riil per pelayanan pasien. Peneliti juga tidak mendapat akses ke laporan biaya RS secara umum, maupun unit cost dari setiap aktivitas pelayanan yang diberikan kepada pasien sehingga pada penelitan ini, digunakan asumsi bahwa tagihan merupakan biaya ditambah 30\% margin. Besar persentase ini sesuai dengan besar persentase margin obat yang berlaku di RS XY berdasarkan informasi dari Kepala Sub Bagian Perbendaharaan.

Kondisi saat penelitian tidak memungkinkan peneliti untuk mengakses berkas rekam medis seluruh sampel. Sehingga dokumen yang ditelaah untuk menilai kesesuaian CP adalah berdasarkan data rekapitulasi yang diunduh dari aplikasi INA-CBG's, laporan transaksi pasien, dan berkas bukti transaksi pasien.

Pada Januari-Maret 2016, RS XY mengalami selisih sebesar Rp. 1.014.125.684,00 dari 207 kasus. Rata-rata selisih per kasus adalah sebesar Rp. 4.899.157,89 sedangkan pada periode yang sama di tahun 2015, RS XY mengalami selisih sebesar Rp. 462.308.506,00 dari 87 kasus, dengan rata-rata selisih sebesar Rp. 5.313.890,87 per kasus. Tampak ada perbedaan rata-rata selisih per kasus antara tahun 2015 dan tahun 2016 sebesar Rp. 414,732.98.

Selanjutnya dari 207 kasus SC pada tahun 2016 maka kasus SC dengan severity level 2 dan kasus yang memiliki kode diagnosis utama maupun diagnosis sekunder yang memerlukan terapi tambahan dikeluarkan. Ekslusi dilakukan pula pada kasus yang prosedur utamanya bukan kode Sectio Caesarea (741), sehingga didapatkan sampel 133 kasus SC tanpa komplikasi.

Kasus yang diambil hanya kasus dengan LOS yang lama rawatnya 3 hari atau kurang dari 3 hari. Dari seluruh kasus SC tanpa komplikasi rata-rata LOS adalah 3,3 hari dengan 16\% kasus memiliki lama rawat melebihi lama rawat $\mathrm{CP}$ yakni 3 hari rawat. Dari 84\% kasus dengan LOS sesuai, 96\% kasus dilakukan visitasi sesuai ketentuan yaitu oleh dokter kebidanan atau dokter umum minimal 1 kali per hari. Sebanyak 21\% kasus memiliki penggunaan obat dan BHP yang sesuai, yaitu yang tidak menambah jenis atau jumlah obat dan BHP dari Paket SC dan/atau CP. Kemudian 48\% kasus memiliki pemeriksaan laboratorium yang sesuai, yaitu tidak menam- bah atau mengurangi pemeriksaan yang ditentukan dalam CP.

Formularium yang digunakan di RS XY merujuk kepada formularium nasional (fornas). Formularium rumah sakit sendiri masih dalam proses pembuatan. RS XY juga telah menentukan kebijakan dalam penggunaan obat dan BHP bagi pasien BPJS termasuk dalam peresepan obat di luar Fornas atau obat mahal. Para dokter sudah diberikan pemahaman bahwa pada pasien BPJS tidak bisa diberikan obat di luar Fornas jika tersedia di dalam fornas dan mereka sudah menyetujui jika Instalasi Farmasi rumah sakit mengganti obat yang diresepkan dengan pengganti yang ada di dalam formularium.

Struktur insentif yang digunakan di RS XY adalah metode Fee For Services dengan pembatasan pada komponen tertentu seperti jumlah maksimal pembayaran jasa visitasi. Di rumah sakit tersebut telah diberlakukan peraturan bahwa jika resume medis tidak dilengkapi dalam batas waktu yang ditentukan maka akan dilakukan pemotongan jasa. Kesepakatan tersebut dapat mempengaruhi besarnya kompensasi yang diterima oleh staf medik fungsional.

\section{Pembahasan}

Tarif INA-CBG's ditentukan berdasarkan case group yaitu kelompok kasus dengan karakter klinis dan kebutuhan sumber daya yang serupa untuk menegakkan diagnosis dan menatalaksana kasus atau untuk menyelesaikan 1 fase perawatan kasus (Cashin et al, 2005). Besaran tarif INA-CBG's tetap sesuai Peraturan Menteri Kesehatan RI sedangkan tarif RS dihitung berdasarkan unit cost dari utilisasi sumber daya yang digunakan untuk menatalaksana kasus. Yang harus dilakukan rumah sakit adalah mengelola biayanya agar sama atau lebih rendah daripada tarif INA-CBG's.

Pada bulan Mei 2015 terjadi pergantian kepemimpinan RS XY dan mulai diterapkan pendekatan baru sebagai upaya cost containment. RS XY membentuk organisasi khusus untuk mengelola pasien BPJS sebagai upaya kendali mutu dan kendali biaya terkait pelayanan. Dalam melakukan tugasnya, tim pengendali JKN merujuk kepada ketetapan yang sudah disepakati rumah sakit. Pergantian kepemimpinan dengan kebijakan barunya serta dibentuknya tim pengendali mungkin menjadi faktor mengecilnya rata-rata selisih kurang pada kasus SC periode Januari-Maret 2016.

Dalam penerapan CP, 84\% kasus memiliki LOS sesuai CP. Seiring perkembangan ilmu kedokteran, rata-rata LOS pasien SC terus mengalami penurunan. 
Pada tahun 1970, rata-rata LOS pasien SC di Amerika adalah 7,8 hari kemudian menurun 49\% pada tahun 1992 menjadi 4 hari (CDC, 1995). Kini, umumnya pasien post SC dirawat selama 2-3 hari. LOS yang terlalu lama tidak efisien dan meningkatkan biaya.

Sepanjang periode Januari sampai Maret 2016 dari seluruh pasien kasus sampel 96\% kasus di-visit sesuai ketentuan CP. Dalam Standar Pelayanan Minimal (SPM) Rumah Sakit tahun 2008, standar pelayanan visitasi dokter spesialis di unit rawat inap adalah pukul 08.00-14.00 setiap hari kerja. Kebijakan mengenai visitasi dokter spesialis pada hari libur, biasanya sesuai dengan kebijakan dari masing-masing rumah sakit.

Berdasarkan telaah berkas rincian transaksi pasien, didapatkan $79 \%$ pasien menggunakan obat atau BHP di luar paket SC. Ketidaksesuaian lebih banyak berupa penambahan obat di luar Paket SC. Obat yang sering ditambahkan adalah penggunaan profilaksis efek samping hipotensi akibat anestesi spinal saat intra operasi. Obat lain di luar paket yang banyak ditemukan adalah obat tekanan darah tinggi dan asma. Ditemukan pula penggunaan antibiotik tambahan yakni metronidazol. BHP yang sering digunakan melebihi yang diberikan adalah benang untuk operasi.

Penggunaan obat di luar paket untuk indikasi penyakit penyerta dapat dibenarkan seperti penggunaan obat hipertensi dan asma. Penggunaan antibiotik tambahan atau pengganti juga ada pada tempatnya jika diberikan pada pasien yang diketahui alergi terhadap antibiotik tertentu atau disertai infeksi yang tidak cocok menggunakan antibiotik yang termasuk dalam paket SC.

Penggunaan profilaksis anestesi di ruang bedah perlu didiskusikan kembali. Saat ini pada lembar checklist CP yang sudah dibuat hanya tertera penggunaan profilaksis midazolam, yang umumnya digunakan sebelum anestesi umum. Penggunaan efedrin sebagai profilaksis anestesi spinal tidak tertera dalam CP. Chinachoti \& Tritrakarn (2007) menemukan dari penelitiannya bahwa kejadian hipotensi (penurunan tekanan darah sistolik sebesar 20\% atau lebih) pada anestesi spinal dengan menggunakan bupivacain adalah sebesar $57,9 \%$ dengan insidens tertinggi terjadi pada kelompok SC. Pada penelitian yang dilakukan Chumpathong (2006), diketahui bahwa angka kejadian hipotensi (tekanan sistolik terendah kurang dari sama dengan $100 \mathrm{mmHg}$ ) pada kasus SC adalah sebesar 76\%. Penelitian lain mengenai efek pemberian efedrin intravena pada kasus SC dapat menurunkan insidens hipotensi (Kol, 2009).

Untuk obat dan BHP yang termasuk dalam paket SC secara umum informan mengetahui adanya pengendalian jika pasien memerlukan obat di luar paket melalui tim pengendali. Instalasi Farmasi juga telah diberikan kewenangan untuk langsung memberikan penambahan obat tertentu pada kasus tertentu namun pihak farmasi kurang mengetahui penggunaan obat dan BHP tambahan di ruang bedah.

Hasil telaah dokumen justru menunjukan bahwa kasus dengan obat atau BHP tambahan lebih banyak daripada kasus yang sesuai dengan paket dan CP. Kemudian didapatkan informasi bahwa ternyata evaluasi untuk obat dan BHP yang masuk dalam Paket SC masih belum berjalan, baik mengenai obat yang berlebih atau obat yang kurang.

Penambahan obat mungkin tidak serta merta membuat biaya membengkak secara siginifikan karena obat dan BHP yang tersedia di Rumah Sakit pun sebagian besar merupakan obat fornas yang didapatkan melalui $e$-catalog dengan harga yang tidak terlalu tinggi. Tetapi penggunaan obat tambahan yang terlalu sering mungkin menunjukkan perlunya evaluasi ulang CP demi menjaga mutu layanan Rumah Sakit.

Pemeriksaan laboratorium dianggap sesuai jika tidak ada pemeriksaan di luar yang sudah ditetapkan CP. Pemeriksaan laboratorium berdasarkan CP adalah pemeriksaan hemoglobin $(\mathrm{Hb})$, leukosit (Leu), trombosit (Tr), hematokrit (Ht), gula darah sewaktu (GDS), dan CT/BT sebelum operasi serta pemeriksaan Hb, Leu, Tr, dan Ht setelah operasi. Berdasarkan telaah dokumen ditemukan bahwa pemeriksaan laboratorium pada $48 \%$ pasien sesuaidenganketentuan CP. Penambahan pemeriksaan yang dilakukan antara lain tes fungsi hati (SGOT/SGPT), fungsi ginjal (Ur/Cr), urin lengkap, dan HBsAg.

Secara umum, CP untuk prosedur tindakan SC di RS XY dirasa belum berjalan dengan optimal. Walaupun semua pihak sudah mengetahui peranannya masing-masing namun angka persentase kesesuaian dengan CP kurang dari 50\% dalam hal pengelolaan obat dan BHP serta pemeriksaan laboratorium. Dari hasil wawancara juga belum nampak adanya sistem evaluasi terstuktur secara berkala untuk penerapan $\mathrm{CP}$ dan penggunaan resource. Belum berjalannya penggunaan checklist $\mathrm{CP}$ mungkin merupakan faktor yang berperan dalam kesesuaian tatalaksana pasien dengan CP. Fungsi checklist, selain sebagai pengingat juga dapat digunakan untuk melakukan evaluasi sederhana dengan mudah.

Obat dan BHP diatur penggunaannya dengan formularium dan diberlakukan kebijakan untuk men- 
gendalikannya RS XY telah menentukan kebijakan dalam penggunaan obat dan BHP bagi pasien BPJS termasuk dalam peresepan obat di luar fornas atau obat mahal. Pergantian obat bermerk yang diresepkan dokter oleh tenaga farmasi sudah diatur dalam Peraturan Pemerintah RI no 51 tahun 2009 tentang pekerjaan kefarmasian Pasal 24b yaitu bahwa apoteker dapat mengganti obat merek dagang dengan obat generik yang sama komponen aktifnya atau obat merek dagang lain atas persetujuan dokter dan/ atau pasien.

Selama 2 tahun beroperasinya RS XY belum memberlakukan sistem remunerasi untuk pembayaran jasa staf medik fungsional. Untuk staf medik fungsional, khususnya dokter spesialis, RS XY menggunakan sistem FFS sedangkan untuk staf lain seperti perawat dan bidan, RS XY menggunakan sistem gaji.

Sadar biaya pada dokter dengan pembayaran kompensasi metode FFS lebih rendah dari pada dokter yang dibayar dengan gaji dan bonus (Tillburt, 2013). Rendahnya perilaku sadar biaya dokter akan berdampak pada keputusan klinis dan akhirnya berdampak pada biaya. Groenewegen \& Calnan (1995) menyatakan remunerasi adalah sistem dapat mendorong kompetisi dan profitabilitas dengan lebih baik. Sistem ini umumnya lebih dipilih agar dapat mengendalikan biaya dengan lebih efisien. Keputusan untuk tetap menggunakan FFS berkaitan dengan sejarah perubahan sistem RS yang sebelumnya merupakan RS swasta. Perubahan ini menuntut manajemen untuk mampu mengantarkan perubahan secara perlahan dan tidak drastis untuk menjaga motivasi pegawai dan pelayanan rumah sakit.

Metode FFS mengkompensasi dokter untuk setiap pelayanan yang diberikan. Dokter yang diberi insentif dengan metode kapitasi akan lebih memilih tatalaksana dengan biaya lebih rendah dan bahwa dokter yang diberi insentif dengan metode FFS akan lebih memilih tatalaksana yang dengan biaya lebih tinggi (Vo, 2013). Sistem FFS yang diterapkan RS XY, mungkin tidak akan meningkatkan biaya secara langsung karena besarannya yang sudah diperhitungkan, yang akan berkurang maupun bertambah sesuai dengan berkurang atau bertambahnya jumlah klaim INA-CBG's. Tetapi metode FFS tidak mendorong perubahan perilaku dokter untuk mengendalikan biaya karena terkendali atau tidak biaya dalam tata laksana pasien tidak dirasakan dampaknya secara langsung oleh dokter.

Setiap perubahan dalam sistem umumnya tidak akan diterima tanpa resistensi. Mengubah sistem FFS menjadi sistem lain baik salary atau remunerasi mungkin disertai keengganan dari staf medik fungsional, sebagaimana hasil penelitian Tilburt (2013) yang menunjukkan $70 \%$ responden dokter tidak antusias mengenai penghapusan sistem pembayaran FFS. Perubahan harus dilakukan dengan perlahan, dan bisa dilakukan dengan melakukan penambahan pada metode FFS dengan menambahkan reward atau punishment dengan indikator yang berorientasi penghematan biaya.

\section{Kesimpulan dan Saran \\ Kesimpulan}

Terdapat selisih antara klaim INA-CBG's dan total tagihan RS untuk 207 kasus SC dengan jaminan BPJS sepanjang Januari-Maret 2016. Total Selisih yang didapat sebesar Rp. 1.014.125.684,00 dengan rata-rata selisih adalah sebesar Rp. 4.899.157,89 per kasus. Jika dibandingkan dengan rata-rata selisih tahun 2015 yang sebesar Rp. 5.313.890,87 per kasus, tampak ada perbedaan rata-rata selisih per kasus dari tahun 2015 dan tahun 2016 sebesar Rp. 414.732,98.

Penerapan CP belum optimal, ditemukan bahwa komponan penggunaan obat dan BHP serta pemeriksaan laboratorium masih belum sesuai dengan CP. Diketahui bahwa checklist CP belum diterapkan dan tidak ada sistem evaluasi terstruktur untuk CP kasus SC.

Walaupun ada standardisasi penggunaan obat yang mengacu kepada fornas dan pengendalian peresepan obat oleh tim pengendali JKN namun masih ditemukan banyak ketidaksesuaian penggunaan obat dan BHP untuk kasus SC. Dan belum ada sistem evaluasi mengenai kekurangan dan kelebihan obat dan BHP dari sistem Paket SC.

masih menggunakan sistem FFS untuk pembayaran jasa staf medik fungsional. Pembatasan yang diberikan berupa ketentuan pembayaran jasa rawat maksimal untuk kasus yang sudah memiliki CP dan pemotongan jasa medis bagi dokter yang tidak mengisi resume medis dengan lengkap dalam kurun waktu yang ditentukan. Struktur insentif FFS yang digunakan pada saat ini tidak cocok diterapkan pada sistem paket tarif INA-CBG's, perlu dipertimbangkan perubahan struktur insentif yang lebih mendorong sadar biaya mengingat besarnya persentase Jasa Pelayanan dalam komponen pembentuk tagihan.

\section{Saran}

Evaluasi kembali CP dan resource yang digunakan dalam hal (1) penggunaan profilaksis anestesi di ruang bedah; (2) jumlah benang yang digunakan; (3) standar pemeriksaan HbsAg sebelum operasi; 
(4) pemeriksaan Leukosit, Tromobosit, dan Hematokrit setelah operasi; (5) menerapkan penggunaan checklist CP dan membuat sistem evaluasi CP secara periodik.

Perlu dilakukan pendataan penggunaan obat dan BHP yang kurang atau berlebihbaik pada tahap pra operasi, intra operasi dan post operasi. Kemudian dilakukan evaluasi kembali untuk memastikan paket obat menggunakan resource yang tidak berlebih dan memberikan mutu pelayanan yang baik. Serta perlu dibuat sistem informasi yang lengkap dan detail untuk mempermudah proses pendataan dan evaluasi, utamanya dalam hal penggunaan resource.

Perlu dilakukan telaah struktur insentif yang mampu meningkatkan budaya sadar biaya kemudian dipertimbangkan untuk melakukan transisi sistem imbal jasa. Perubahandari FFS menujuremunerasisebaiknya dilakukan dengan perlahan dan bisa dimulai dengan memberikan penambahan pada metode FFS misal dengan menyertakan reward dan/atau punishment dengan indikator yang berorientasi pengendalian biaya.

\section{Daftar Pustaka}

American Society of Health-System Pharmacists. (2008). ASHP guidelines on medication cost management strategies for hospitals and health systems. Am J Health-Syst Pharm, 65:1368-84.

Carrin, G., dan Hanvoravongchai, P., (2002). Health care cost-containment policies in high-income countries: how successful are monetary incentives? World Health Organization Geneva.

Cashin C, et al. 2005. Case-based hospital payment systems: a step-by-step guide for design and implementation in low- and middle-income countries. United States Agency for International Development.

Centers for Disease Control and Prevention. 1995. Trends in Length of Stay for Hospital Deliveries - United States, 1970-1992. Morbidity and Mortality Weekly Report. May 05, 1995 / 44(17);335-337.

Chinachoti T \& Tritrakarn T. 2007. Prospective study of hypotension and bradycardia during spinal anesthesia with bupivacaine: incidence and risk factors, part two. J Med Assoc Thai. 2007 Mar;90(3):492-501.

Chumpathong $S$ et al. 2006. Incidence and risk factors of hypotension during spinal anesthesia for cesarean section at Siriraj Hospital. J Med Assoc Thai. Aug;89(8):1127-32.
De Bleser, L., et all. (2006). Defining Pathways. Journal of Nursing Management, 14, 553-63.

Ensor, T., \& Indrajaya, S., (2012). The costs of delivering health services in Indonesia: Report on a prospective survey 2010-2011. Depkes RI, Jakarta

Garber, A., Goldman, D.P., and Jena, A.B., (2007). The promise of health care cost containment. Health Affairs, 26, no.6:1545-7

Groenewegen, P.P., \& Calnan M., (1995). Changes in the control of health care systems in europe implication for professional autonomy. European journal of public heatlh, 5: 240-244

Horngren, C.T., Datar, S.M., \& Rajan, M.V., (2015), Cost accounting a managerial emphasis, $15^{\text {th }}$ edn, Pearson Edcation Inc., Upper Saddle River, New Jersey.

Javid M., et al. (2015). Application of the activity-based costing method for unit-cost calculation in a hospital. Global Journal of Health Science; Vol. 8, No. 1; Canadian Center of Science and Education

Kinney, M.R., Raiborn C.A., (2011). Cost Accounting: Foundations and Evolutions, $8^{\text {th }}$ ed. South-Western Cengage Learning.

Kol IO, et al. 2009. The Effects of Intravenous Ephedrine During Spinal Anesthesia for Cesarean Delivery: A Randomized Controlled Trial. J Korean Med Sci. 2009 Oct; 24(5): 883-888.

Pena, A.D., \& Ndiaye M., (2003). Cost control, a myth or reality: do hospital costs really go down when quality goes up? World Hospitals and Health Services. Vol.40 No.1 p28-32

Putri, A.E., (2014), Paham JKN Jaminan Kesehatan Nasional, Friedrich-Ebert-Stiftung

Tilburt JC, et al. (2013). Views of US Physicians About Controlling Health Care Costs. JAMA. 2013;310(4):380-388

Vo, AV. 2013. Working Hard or Hardly Working? The Effects of Pay Structure on Cost of Healthcare Provision. Carlson School of Management, University of Minnesota. 